\title{
A MANUAL THERAPY APPROACH TO THE NECK PAIN DUE TO ABNORMAL HEAD POSITION
}

\author{
Marius S. POP ${ }^{1 凶}$, Petru MIHANCEA ${ }^{2}$, Daiana DEBUCEAN ${ }^{1}$ \\ ${ }^{1}$ Linea Medica Clinic, Oradea, Romania \\ ${ }^{2}$ Doctoral School of Biomedical Sciences, University of Oradea, Romania
}

Received 11 July 2018, Accepted 23 Aug 2018

https://doi.org/10.31688/ABMU.2018.53.3.16

\begin{abstract}
Introduction. Neck pain (NP) is an increasingly common symptom among the general population, regardless of age, but predominantly in women. Most studies confirm the direct links between this symptom and the biomechanical changes in the cervical spine, induced by postural problems.
\end{abstract}

Objectives. To identify the mechanisms of maintaining the cervical symptoms in patients with abnormal head position, as well as the benefits and limitations of manual therapy for these dysfunctions and also to suggest and develop complementary or substitutive solutions to the used therapies.

Methods. 51 patients were included in the study. We used the Assessment Card for the Patient with Cranio-Cervical-Mandibular Dysfunctions, the Visual Analog Scale, the Cervical Flexion-Rotation Test, Rocabado's, Romberg's and Fukuda's functional tests, Kirby's and Root's Biomechanical Foot Assessment Cards, Static and Dynamic Computed Baropodometry, Palmerini's Cranio-Cervical-Mandibular Functional Assessment and the Visual Acuity Difference test developed by Giannelli.

Results. The total extinction of the NP was found in $49 \%$ of the subjects, the stabilization of the upper cervical spine in $64.7 \%$ of them, while $56.8 \%$ of the

\section{Résumé}

Une approche manuelle de la thérapie de la douleur causée par la position anormale de la tête

Introduction. La douleur cervicale est une manifestation clinique de plus en plus fréquente parmi la population générale, quelque soit l'âge, mais principalement chez les femmes. La plupart des études confirment les liens directs entre cette douleur et les altérations biomécaniques au niveau de la colonne cervicale induites par les problèmes posturaux.

Les objectifs. La démonstration des mécanismes à travers lesquels on entretient la symptomatologie cervicale aux patients avec position anormale de la tête, des avantages et des limites de la thérapie manuelle adressée à ces dysfonctions et aussi la proposition et le développement des solutions complémentaires ou substitutives aux thérapies utilisées.

Méthodes. On a administré, sur un lot de 51 patients, les instruments d'évaluation et de surveillance suivants: La Fiche d'Évaluation du Patient avec des Dysfonctions Cranio-Cervico-Mandibulaires, Visual Analog Scale, Cervical Flexion-Rotation Test, les tests fonctionnels Rocabado, Romberg, Fukuda, L'Évaluation biomécanique du pied selon Kirby et Root, Baropodométrie Computérisée statique et dynamique, L'Évaluation 
patients of our study neglected to treat the primary extra vertebral cause of their cervical instability.

Conclusions. Removing the extra vertebral factors that cause head position changes and implicitly NP, followed by cranio-cervical-mandibular manual therapy, results in significant improvement in the postural syndrome and the reduction of the painful symptoms.

Keywords: abnormal head position, neck pain, manual therapy.

Abbreviations. AHP - abnormal head position, NP neck pain, MT - manual therapy

\section{INTRODUCTION}

Recent international epidemiological studies ${ }^{1,2}$ confirm an increasing incidence of patients with neck pain (NP) because of degenerative processes in the cervical spine, involving all types of tissues at this lev$\mathrm{el}$, from the soft tissue (myofascial, vascular, nervous) to the osteo-articular one $e^{3,4}$.

It is already known that most degenerative processes in the cervical spine ${ }^{5}$ are in the lower rachis, because of some biomechanical dysfunctions at the level of the upper rachis induced by postural problems $\mathrm{s}^{6.8}$ and some diseases of the stomatognathic system ${ }^{9-11}$.

This study suggests a more detailed approach to the primary causes that lead to abnormal head position (AHP) ${ }^{12-14}$, both in terms of diagnosis and therapeutic perspective, identifying the obstacles in the therapeutic approach, on the way from a primary cause to the cervical effect.

Abnormal or compensatory head position means any deviation of the median line of the head from the median line of the body ${ }^{15}$ or any deviation of the bipupillar line ${ }^{16,17}$ from the horizontal line of the space (in the anterior frontal plane); in the sagittal plane, any misalignment of the tragus, considered by $\operatorname{Bricot}^{18}$ a reference point in the alignment of the body on an imaginary sagittal line (also called the gravitational line). This positional abnormality is also found in the transverse plane ${ }^{19}$ of the head (the bitragal line) relative to the scapular transverse plane, respectively to the transverse plane of the basin - considering the physiological asymmetries and the dominance (arm, eye, lower limb) of everyone in part. In frontal and sagittal planes ${ }^{20}$, the position of the skull may also be assessed by means of photography and/or Imagistics
Fonctionnelle Cranio-Cervico-Mandibulaire Palmerini et Visual Acuity Difference Giannelli.

Résultats. On a constaté la disparition totale de la douleur cervicale chez $49 \%$ des patients et la stabilisation de la colonne vertébrale cervicale supérieure chez $64,7 \%$, tandis que $56,8 \%$ des patients étudiés ont négligé de résoudre la cause primaire extra-vertébrale de l'instabilité cervicale.

Conclusions. L'élimination des facteurs extra-vertébraux qui causent des altérations de la position de la tête et, implicitement, la douleur cervicale, suivie d'une thérapie manuelle cranio-cervico-mandibulaire qui a comme résultat l'amélioration significative du syndrome postural et la disparition des symptômes douloureux.

Mots-clés: position anormale de la tête, douleur cervicale, thérapie manuelle

by calculating the cranio-cervical angle or the suboccipital space ${ }^{21}$.

The OBJECTIVES OF OUR STUDY were to demonstrate the direct links between NP and AHP, on the one hand, to identify the limits of the most effective and modern non-invasive therapeutic methods ${ }^{22-26}$ used in patients with biomechanical origin of the NP, methods aimed at a pathology that is almost always secondary to distant or proximal causes, and to suggest and develop complementary or substitutive solutions to the therapies used, on the other hand.

\section{Material AND Methods}

The study was conducted at the Linea Medica Clinic in Oradea, Romania, between June 2017 and June 2018, on a group of 51 patients, including 16 men (31.37\%) and 35 women (68.63\%), aged between 8 and 67 years. The age span is very broad, but we studied all patients who sought help in our service and met the inclusion criteria, gave their written consent to participate in the study, and were compliant to the study requirements. The professions and hobbies of the subjects are of the most diverse, without identifying any motor pattern that predominates and which can prove direct causality. Patients belong to one of the following four categories:

a. with AHP induced by a pathology of the visual system (convergence issues, astigmatism, refractive errors): 5

b. with AHP induced by an occlusal pathology: 20

c. with AHP induced by mouth breathing (with or without swallowing issues): 6 
d. with AHP of cervical origin (primary C1-C2 vertebral rotations, axial changes in postural context): 20 Inclusion factors: NP and AHP.

Exclusion factors: traumas, central neurological pathologies, malformations, disorders in the sphere of psychiatry, poor collaboration with the team of professionals involved in the study.

The following assessment methods were used: the Assessment Card for the Patient with Cranio-Cervical-Mandibular Dysfunctions, developed by the first author of the present study, based on the Diagnostic Criteria for Temporomandibular Disorders (DC/TMD) ${ }^{27}$; the Visual Analog Scale (VAS); the Cervical Flexion-Rotation Test (CFRT); Rocabado's, Romberg's and Fukuda's functional tests; Kirby's and Root's Biomechanical Foot Assessment Cards ${ }^{28}$; Static and Dynamic Computed Baropodometry; Palmerini's Cranio-Cervico-Mandibular Functional Assessment and the Visual Acuity Difference (VAD) test developed by Giannelli29 .

The Assessment Card for the Patient with Cranio-Cervical-Mandibular Dysfunctions aims to identify the primary causes (ophthalmic, occlusal and other functions of the stomatognathic system), determining the status of these causes (active or inactive at the time of evaluation), the impact that these causes may have on the cervical spine and the differential diagnosis for comorbidities (in case of suspicion, the patient is directed to medical professionals with competence in the appropriate specialties - orthodontics, ophthalmology, otorhinolaryngology, neurology, psychiatry). It is also very useful in developing a personalized therapeutic plan addressing the primary cause and the effects (only after excluding comorbidity or after a correct assessment of the initial pathology made by a professional, when necessary). The Assessment Card for the Patient with Cranio-Cervical-Mandibular Dysfunctions was developed by the first author of this study based on international diagnostic criteria and the clinical experience gained in the assessed and monitored patient groups and it is continuously optimized since 2015.

Based on the clinical-functional and instrumental evaluation, an AHP and a NP with a major myofascial component were confirmed (in all subjects under study), as demonstrated by us previously, in a study of 174 subjects. In the group of 51 patients enrolled in the study, 8 were diagnosed with cervical discopathy, 2 of them with specific symptomatology (upper limb paresthesia) overlapped with NP of myofascial origin.

The same therapeutic protocol was applied to all categories of patients: treatment for the primary altered function and for the compensatory involved segment. The therapeutic protocol consisted of cranio-cervical-mandibular manual therapy (based on
Rocabado, Stecco and Mulligan concepts) and postural overall rehabilitation (based on Suchard concept). The duration of the therapy was 8 weeks, with a frequency of 2 sessions of 40 minutes per week. It is very important to emphasize that during the therapy, patients had not undergone other treatments (medication, physiotherapy, alternative therapies, etc.)

\section{Results AND Discussions}

Following the therapeutic protocol, subjective (decrease in pain intensity) and objective (postural) improvements were obtained.

Significant reduction in NP due to myofascial component was found in patients who received treatment for the identified primary cause (visual system, occlusion and mouth breathing) and those who had strictly an imbalance at the cervical level. In these two categories of patients, the stability of the upper cervical junction was maintained for medium and long term and any neurological phenomena (paresthesia) originating in the inferior rachis were reduced up to extinction, all along with a significant improvement in the head alignment to the rest of the body segments (in static and dynamic moments).

In the category of patients with alterations of the visual system - and here we refer to the most „neglected" ones, which sometimes can easily get out of sight, but induce significant alterations of the position of the head and the cervical spine, such as astigmatism and ocular convergence disorders -, the extinction of the NP was achieved in 4 out of 5 patients. In 2 out of 5 patients in this category the result was, in addition, the optimization of the head position in the sagittal and frontal plane relative to the biomechanical balance of the cervical spine.

In patients with dental-occlusal problems as a primary cause, out of the 20 subjects, 5 are under orthodontic treatment, the other 15 haven't yet been to an orthodontist for evaluation and specific treatment. Of the total of 8 stable patients in this category, 3 received specific treatment for the primary cause. Performing specific therapy for the primary cause provides a $60 \%$ success rate, whereas the lack of primary therapy leads to only a $33.3 \%$ success rate in NP therapy. We therefore believe that specific manual therapy optimizes cervical biomechanics with impact on painful syndrome, but cervical stabilization is not sustained in the long run due to the presence of the unresolved primary cause.

Two of the 6 patients who had mouth breathing as primary cause received, along with cranio-cervical manual therapy, specific treatment for respiratory pattern correction (myofunctional therapy provided by a speech therapist). At the end of the therapy sessions, 
the 2 patients experienced a significant improvement in head position and postural alignment in a global context compared to the other 4 patients who had modest improvements (1 patient) or had no objective improvement in this effect ( 3 patients). Therefore, although on a very small number of patients, statistics say that those who addressed the primary cause were $100 \%$ successful and those who neglected the primary cause had a $75 \%$ failure.

Thus, in the category of patients who postponed or refused specific therapy for the primary non-vertebral causes that lead to AHP, as mentioned above, subjective recurrence (recurrence of pain, including neurological phenomena in patients presenting cervical discopathy) as well as objective recurrence (modest results or even lack of results) were noted.

The fourth category of patients, those with imbalance in the upper cervical spine without alterations of other receptors, the cranio-cervical manual therapy has been effective in reducing both the painful syndrome and the cranio-cervical and postural imbalance. Statistically, the situation is as follows: 16 stable patients (80\%) and 4 unstable patients (20\%) from a biomechanical point of view. Of those with cervical stability, 2 patients are still symptomatic (show NP), i.e. $12.5 \%$, while the remaining 14 , i.e. $87.5 \%$, are asymptomatic (NP absent or at an extremely low level, as reported). On the other hand, all 4 patients with cervical instability still have painful syndrome (100\%).

Since myofascial restrictions at the base of the skull have a strong influence on cervical spinal biomechanics, often defining the maturation and morphological structuration of the bone tissue, even in the skull and mandible, the rehabilitation of these dysfunctions is a challenge, although we call concepts already validated by the international scientific community, with proven clinical effectiveness. In the case of the 4 patients with cervical instability, the tissues did not allow the complete regaining of the flexion and physiological rotation at the upper cervical junction, among the possible explanations being the particularities of the tissue and the time allocated for the therapy (8 weeks).

A situation of interest for future studies is represented by the two patients with stability at the cranio-cervical level, but who still have NP. Without other indications of objective influences, we can suspect the involvement of psycho-emotional factors, which results from anamnesis, but requires specific and detailed psychological assessment.

On the other hand, we have the cases of the 8 patients with cervical discopathy, 2 of them with upper limb paresthesia. One of these 2 was diagnosed with C4-C5, C5-C6 disc hernias. Although their situation seemed to be difficult to control (clinical and imagistic) at the level of symptoms, they responded extremely favorably to cranio-cervical MT, achieving stability in the upper cervical spine, in both patients, with total extinction of the NP in one patient and with significant improvements in the patient with the herniated discs.

The results are closely dependent on the approach of the primary extra vertebral cause, where it exists, and which significantly influences the position of the head and implicitly the painful symptoms associated with the malposition. Unfortunately, 29 of the 51 subjects $(56.8 \%)$ did not show interest in treating the extra vertebral cases until the end of the study, although the existence of these causes was confirmed by the assessment tools used and by the physician in the appropriate specialty. The extinction of the NP was recorded in 25 patients (49\%) and the cervical stability in 33 of the patients under study (64.7\%). These percentages are relevant and promising, considering that only $43.2 \%$ have gone through all the stages required for complete diagnosis and treatment.

We believe that the results are satisfactory, even if, in some cases, they only cover the patient's expectations of symptom relief. We continue to encourage patients to address the professionals, assuming the fact that only interdisciplinary collaboration can produce long-term or even lifetime lasting results.

The evolution of the results was recorded in the Assessment Card for the Patient with CranioCervical-Mandibular Dysfunctions, Monitoring section.

\section{THE LIMITS OF THE STUDY}

The main limitation of the study is the low number of subjects, which does not reduce its scientific value, but may draw criticism on its statistical value. We are already working on overcoming this limitation, continuing the same methodology, with the inclusion of new subjects for a broader and more statistically significant study.

Another limit has been identified in the relatively small number of patients who undergone psychological assessment (here we have faced the reluctance of some of them), which we consider extremely important for a better understanding of the subjective component.

\section{Conclusions}

1. Degenerative processes in the lower cervical spine are installed on the background of instability or hypermobility, induced by a hypomobility at the level of the upper spine, a situation we find in almost all cases of AHP. 
2. Fascicular restrictions at the base of the skull and constant maintenance of an AHP may cause frequent pain syndromes of very high intensity associated with cervicogenic secondary headache.

3. The fastest indicator of a risk factor for early degeneration of inferior cervical structures is the AHP. Not always this malposition of the cranial-cervical segments is transcended by pain or degenerative phenomena, but these effects, once installed, in the absence of local traumas, malformations or autoimmune diseases, are directly related to a malposition of the head.

4. The use of the Assessment Card developed by us refines the diagnostic approach, so we are working on its validation in Romanian population.

5. In view of the increased incidence of NP and the neglect of the biomechanical aspects of its origin, we believe that adopting this approach would be useful for the effective control of secondary disabilities of this condition, the psychosocial impact and implicitly the costs of diagnosis and therapy of this pathology.

\section{Compliance with Ethics Requirements:}

"The authors declare no conflict of interest regarding this article"

„The authors declare that all the procedures and experiments of this study respect the ethical standards in the Helsinki Declaration of 1975, as revised in 2008(5), as well as the national law. Informed consent was obtained from all the patients included in the study"

"No funding for this study"

\section{References}

1. Cohen SP. Epidemiology, diagnosis, and treatment of neck pain. Mayo Clinic Proceedings 2015;90(2):284-299.

2. Depintor JD, Bracher ES, Cabral DM, Eluf-Neto J. Prevalence of chronic spinal pain and identification of associated factors in a sample of the population of São Paulo, Brazil: cross-sectional study. Sao Paulo Medical Journal 2016;134(5):375-384.

3. Markotić V, Zubac D, Miljko M, et al. Level of education as a risk factor for extensive prevalence of cervical intervertebral disc degenerative changes and chronic neck pain. Central European Journal of Public Health 2017;25(3):245-250.

4. Hoy DG, Protani M, De R, Buchbinder R. The epidemiology of neck pain. Best Practice $\mathcal{B}$ Research: Clinical Rheumatology 2010;24(6):783-792.

5. Dos Santos Genebra CV, Maciel NM, Frascareli Bento TP, Penteado Simeão SFA, De Vitta A. Prevalence and factors associated with neck pain: a population-based study. Brazilian Journal of Physical Therapy 2017; 21(4):274-280.

6. Sarquis LM, Coggon D, Ntani G, et al. Classification of neck/shoulder pain in epidemiological research: a comparison of personal and occupational characteristics, disability, and prognosis among 12,195 workers from 18 countries. Pain 2016;157(5):1028-1036.

7. Brink Y, Louw Q, Grimmer K, Jordaan E. The relationship between sitting posture and seated-related upper quadrant musculoskeletal pain in computing South African adolescents: A prospective study. Manual Therapy 2015; 20(6):820-826

8. Meziat-Filho N, Azevedo E Silva G, Coutinho ES, Mendonça $\mathrm{R}$, Santos V. Association between home posture habits and neck pain in High School adolescents. Journal of Back and Musculoskeletal Rehabilitation 2017;30(3):467-475.

9. An JS, Jeon DM, Jung WS, Yang IH, Lim WH, Ahn SJ. Influence of temporomandibular joint disc displacement on cranio-cervical posture and hyoid bone position. American Journal of Orthodontics and Dentofacial Orthopedics 2015;147(1):72-79.

10. Bragatto MM, Bevilaqua-Grossi D, Regalo SC, Sousa JD, Chaves TC. Associations among temporomandibular disorders, chronic neck pain and neck pain disability in computer office workers: a pilot study. Journal of Oral Rehabilitation 2016;43(5):321-332.

11. La Touche R, París-Alemany A, von Piekartz H, Mannheimer JS, Fernández-Carnero J, Rocabado M. The influence of cranio-cervical posture on maximal mouth opening and pressure pain threshold in patients with myofascial temporomandibular pain disorders. The Clinical Journal of Pain 2011;27(1):48-55.

12. Mowatt L, Gordon C, Santosh ABR, Jones T. Computer vision syndrome and ergonomic practices among undergraduate university students. International Journal of Clinical Practice 2018;72(1).

13. Sabatucci A, Raffaeli F, Mastrovincenzo M, Luchetta A, Giannone A, Ciavarella D. Breathing pattern and head posture: changes in cranio-cervical angles. Minerva Stomatologica 2015;64(2):59-74.

14. Daly L, Giffard P, Thomas L, Treleaven J. Validity of clinical measures of smooth pursuit eye movement control in patients with idiopathic neck pain. Musculoskeletal Science \& Practice 2017;33:18-23.

15. Erkan Turan K, Taylan Șekeroğlu H, Koç I, et al. Ocular causes of abnormal head position: strabismus clinic data. Turkish Journal of Ophthalmology 2017;47(4):211-215.

16. de Pádua M, Sauer JF, João SMA. Quantitative postural analysis of children with congenital visual impairment. Journal of Manipulative and Physiological Therapeutics 2018;41(1):62-70.

17. Bricot B. La Riprogrammazione Posturale Globale, Marseille, Statipro, 1998:120.

18. Bricot B. La Riprogrammazione Posturale Globale, Marseille, Statipro, 1998:18.

19. Bricot B. La Riprogrammazione Posturale Globale, Marseille, Statipro, 1998:27.

20. Ling FP, Chevillotte T, Leglise A, Thompson W, Bouthors C, Le Huec JC. Which parameters are relevant in sagittal balance analysis of the cervical spine? A literature review. European Spine Journal 2018;27(1):8-15.

21. Bedoya A, Landa Nieto Z, Zuluaga LL, Rocabado M. Morphometry of the cranial base and the cranial-cervical-mandibular system in young patients with type II, division 1 malocclusion, using tomographic cone beam. The Journal of Craniomandibular $\mathcal{E}$ Sleep Practice 2014;32(3):199-207.

22. Ganesh GS, Mohanty P, Pattnaik M, Mishra C. Effectiveness of mobilization therapy and exercises in mechanical neck pain. Physiotherapy Theory and Practice 2015;31(2):99-106. 
23. Hall T, Chan HT, Christensen L, Odenthal B, Wells C, Robinson K. Efficacy of a C1-C2 self-sustained natural apophyseal glide (SNAG) in the management of cervicogenic headache. Journal of Orthopaedic $\mathcal{E}$ Sports Physical Therapy 2007;37(3):100-107.

24. Lomas-Vega R, Garrido-Jaut MV, Rus A, Del-Pino-Casado R. Effectiveness of global postural re-education for treatment of spinal disorders: a meta-analysis. American Journal of Physical Medicine E Rehabilitation 2017;96(2):124-130.

25. Pillastrini P, Banchelli F, Guccione A, et al. Global postural re-education in patients with chronic nonspecific neck pain: cross-over analysis of a randomized controlled trial. La Medicina del Lavoro 2018;109(1):16-30.

26. Kim BB, Lee JH, Jeong HJ, Cynn HS. Effects of suboccipital release with cranio-cervical flexion exercise on cranio-cervical alignment and extrinsic cervical muscle activity in subjects with forward head posture. Journal of Electromyography \& Kinesiology 2016;30:31-37.

27. Schiffman E, Ohrbach R, Truelove E, et al. Diagnostic criteria for temporomandibular disorders (DC/TMD) for clinical and research applications: recommendations of the International RDC/TMD Consortium Network ${ }^{*}$ and Orofacial Pain Special Interest Group. Journal of Oral $\mathcal{E}$ Facial Pain and Headache 2014; 28(1):6-27.

28. Glaser ES, Fleming D. Foot posture biomechanics and MASS theory. The Foot and Ankle Online Journal 2016;9(1):12.

29. Palmerini V, Giannelli L. Disfunciónes visuales, estomatognáticas y posturales: interferencias y métodos diagnósticos. Paper presented at: the XVIIth Sociedad Española De Kinesiologia Médica Odontológica (Sekmo) Congress, October, 26-27-28, 2017, Bilbao, Spain. 